\title{
Tres versiones literarias de una conspiración
}

\author{
Adriana Sandoval
}

Resumen: El visitador Muñoz llegó a la Nueva España con otro funcionario, encargados ambos de arreglar lo que la Audiencia consideraba un mal manejo de la llamada conspiración independentista del marqués del Valle. Hay distintas versiones de su conducta, pero en la obra de teatro de Rodríguez Galván, dos capítulos de El libro rojo de Riva Palacio y un cuento anónimo — todos del siglo $\mathrm{XIX}$-, el visitador aparece como un dictador cruel y arbitrario. El personaje sirvió, en estos casos, como pretexto para validar la independencia de México y criticar al gobierno real y sus funcionarios.

AвSTRACT: "Visitador" Muñoz arrived to New Spain to oversee how the newly appointed viceroy had managed a conspiration to overthrow the government. There are three literary versions of the government official (a play, two historical chapters in a book, and an anonymous short story) which emphasize his cruelness. The literary treatment of this character contributed to validate Mexican Independence, criticizing the Spanish King and his officers.

Palabras Clave: visitador Muñoz; época colonial; siglo XIX mexicano; independencia mexicana.

KeYwords: Visitador Muñoz; Colonial Period; Mexican Nineteenth Century; Mexican Independence.

FeCHA De ReCEPCIÓn: 24 de marzo de 2014 FECHA DE ACEPTACIÓN: 20 de agosto de 2014 



\title{
Tres versiones literarias de una conspiración
}

\author{
Adriana Sandoval \\ Instituto de Investigaciones Filológicas, UNAM \\ asandola@yahoo.com.mx
}

Los tres textos de los que me ocupo se centran en la figura de Antonio Muñoz, en el momento en que llega a la Nueva España en 1568 para juzgar la conducta del virrey marqués de Falces. Si bien hay algunas diferencias en las versiones, la mayor parte coincide en presentar a este visitador como un hombre arbitrario y autoritario. Así, la intención de sentido parece ser la de destacar la crueldad de un funcionario del Estado espańol, nombrado por el rey, lo cual subrayaba la necesidad, post facto, de la Independencia. Centrar la atención sobre este personaje, pintado claramente como villano, establece un enemigo común, externo, frente al cual los habitantes de la Nueva Espańa podrían unirse, emocionalmente o por medio de las armas. En cuanto a los lectores contemporáneos de los autores, parecería buscarse la reacción reafirmativa del movimiento de Independencia.

Sin embargo, esta visión negativa de Muñoz no es ya, por ejemplo, el lente desde el cual se considera a este personaje en nuestros años. En el artículo "Alonso Muñoz, consejero de Indias", Carmen Martínez Ríos sigue la amplia carrera de este funcionario e incluso de su familia, después de su muerte. Esta autora menciona muy de pasada la crueldad del visitador, contrastada con la de otro de los visitadores, Carrillo, el funcionario que viajó con él a la Nueva España a resolver los problemas políticos que empezaban a afectar la economía y el comercio de la Corona. En el recorrido que hace Martínez de la vida de Muñoz, el asunto de su supuesta crueldad es un asunto menor, frente a la larga y exitosa carrera que había tenido como funcionario: baste ver el título del artículo, donde el énfasis se coloca en su papel como consejero de Indias. La autora usa como fuente el libro de Juan Suárez de Peralta, Tratado del descubrimiento de las Indias y su conquista. Este tratado fue escrito en 1589 y apenas rescatado a fines del siglo xIx. No deja de ser interesante que, si bien Suárez de Peralta menciona la crueldad de Muñoz, tampoco es, para él, ni remotamente el principal rasgo de su carácter. En su versión, las variaciones con respecto a Manuel Orozco y Berra 
y Torquemada, son mayores. Por ejemplo, la ya mencionada crueldad de Muñoz, que en los textos a los que hago referencia en el cuerpo del artículo es fundamental, queda en sospecha en la de Suárez de Peralta e incluso se la atribuye, como posibilidad, a Carrillo — si bien sí se acepta que Muñoz tenía esa fama (Suárez de Peralta: 233). Por no haber sido fuente de los textos aquí comentados, no me ocupo en detalle de esta versión. Baste decir que apunta a lo resbaladizo de las distintas versiones de los hechos, y a la decisión de adoptar una u otra fuente histórica para realizar una versión literaria e incluso, al elegir una versión, llevar a cabo una selección de fragmentos y luego recrearlos.

Las formas literarias de presentación de los textos aquí comentados son distintas: estamos frente a una obra de teatro, dos artículos (o capítulos de libro) y un cuento.

1) La obra de teatro (1838) es de Ignacio Rodríguez Galván. Muñoz, visitador de México.

2) Dos capítulos de la autoría de Vicente Riva Palacio, incluidos en Manuel Payno y Vicente Riva Palacio, El libro rojo, 1870.

3) Anónimo, "El visitador", en dos entregas en El Tiempo. Diario Católico.

Si bien la distancia temporal entre las tres versiones es de casi treinta años en cada caso, se justifica agruparlas, dado que se ocupan del mismo personaje. Además, compartieron fuentes informativas. En el caso de la obra de teatro y el cuento, hay un claro diálogo entre ambos, puesto que el cuento da por bueno y recrea la anécdota central - ficticia, por cierto- del drama.

Una de las fuentes explícitas del segundo de estos textos es el libro más amplio y documentado sobre el tema, de Manuel Orozco y Berra: Noticia histórica de la conjuración del marqués del Valle. Años 15651568, basado en documentos legales. Orozco elige y resume, conserva la ortografía, pero coloca signos de puntuación para agilizar la lectura. Asimismo, pone notas aclaratorias cuando considera que así lo amerita algún pasaje. Lamentablemente falta, aclara, un "cuaderno principal, que contenía la información hecha por la audiencia, las denuncias, los documentos comprobantes de la trama, las sentencias pronunciadas contra los reos" (viii). 
Pese a ello, afirma, es claro "lo relativo a una conjuración, que a manera de una semilla depositada en la raza criolla, vino con el tiempo a dar el fruto de la guerra de 810 y la independencia de México" (ix). Este historiador escribe primero una larga introducción a los documentos que luego incluye y publica, contando, de una manera muy similar a la de una narración literaria, lo sucedido durante esta conspiración. Recordemos que durante el siglo xIx la frontera entre historiadores y literatos no era tajante y ambos se congregaban bajo el mismo título de hombres de letras. Orozco y Berra menciona a quienes se ocuparon antes de la conspiración, destacando la Monarquía indiana de Torquemada. El fraile, apunta el historiador, nunca afirmó haber leído los autos, y más bien parece basar su recuento en opiniones y comentarios. Su versión, concluye, "era en parte verdadera y en parte falsa" (xii).

Con respecto a las opiniones del proceso, Orozco afirma que hay diferencias notables en la actitud de parte de los contemporáneos al suceso y de quienes se ocuparon de él cuando México había dejado ya de ser la Nueva España. Orozco estaba ya consciente de cómo distintas personas van alterando las versiones de lo sucedido, o las interpretaciones, de acuerdo a su momento, su contexto y sus intereses.

Para la redacción de su "artículo histórico", Orozco recurrió primero a Torquemada y su Monarquía indiana, "pero el examen de su relación no me dejó contento, porque encontré que si bien estábamos conformes en mucho de lo relativo a los hechos, debíamos diferir en cosas esenciales, hasta venir a muy distinto relato, y diferente juicio de las causas que influyeron en la conjuración" (x). Cavo, añade, en sus Tres siglos, ${ }^{1}$ "casi no hizo más de copiar a Torquemada, ${ }^{2}$ lo mismo que an-

${ }^{1}$ Se refiere a Andrés Cavo (1739 Guadalajara, 1803 Roma), jesuita, autor de Historia civil y politica de México, editada luego en México como Los tres siglos de México bajo el gobierno español hasta la entrada del Ejército Trigarante, en cuatro tomos, con el agregado de la parte correspondiente al periodo que termina en 1821, escrito por Carlos María Bustamante (Musacchio 1989).

${ }^{2}$ Dado que Orozco parece ser el historiador más serio, por haberse ocupado de leer las actas existentes del proceso, no resumo la versión de Torquemada, que ciertamente difiere en varios puntos. En internet se puede consultar la versión completa de la $\mathrm{Mo}$ narquia indiana, en espléndida edición de Miguel León-Portilla, que además contiene algunos artículos del propio especialista y otros estudiosos del tema, <http://www. historicas.unam.mx/publicaciones/publicadigital/monarquia/volumen/02/mi_vol02. html\#Libro05> (29/10/2012). Véase en particular el capítulo XIX del Libro V. 
tes había hecho Vetancurt: ${ }^{3}$ el artículo de don Ignacio Cubas, ${ }^{4}$ en el Registro trimestre, ${ }^{5}$ tiene sólo añadido el informe del marqués de Falces que, de paso sea dicho, no estaba dirigido al rey como allí se asegura, sino a la audiencia" (x). El doctor Mora y los siguientes historiadores, consigna, se han basado en el mismo Registro trimestre. Así, el origen de estos recuentos es la versión de Torquemada, que, afirma Orozco, "no se conforma con la de los autos" (xi). Por ello, dice, su resumen se basará en éstos y no en el recuento del franciscano.

Me interesa centrarme en el personaje que tanto llamó la atención de Rodríguez Galván, Manuel Payno, y del autor anónimo del cuento "El visitador Muñoz". Inicia Orozco con una descripción de éste: "hombre de edad, era altivo y cruel; la dureza de sus facciones apartaba de sí descontentos y humillados a quienes se le acercaban, y su presencia tenía algo de penoso y repugnante" (58). Dando marcha atrás a la blandura con la que Falces se había ocupado de la conspiración, Muñoz recapturó a varios de los caballeros que ya estaban libres; y apresó a varios más. El visitador mandó incautar las propiedades del marqués del Valle.

Falces, por su parte, tuvo que presentarse, como cualquier acusado, ante el temible tribunal de Muñoz. Al virrey no se le dictó condena, sino que se dispuso que su proceso se siguiera ante la Corona. Muñoz, previsiblemente, se hizo cargo del gobierno, "sin reconocer freno ninguno" (62). La población entera empezó a vivir bajo la zozobra del temor al tirano. Algunas de las quejas llegaron a oídos de la Corona. Para solucionar el nuevo problema, Felipe II nombró a Villanueva y Vasco de Puga, para ir a México y deponer a Muñoz. El gobierno de la Nueva España pasaba de una crisis a otra.

${ }^{3}$ Fray Agustín de Vetancurt (1620-1700). Fraile franciscano, autor de Arte para aprender la lengua mexicana (1673), Teatro mexicano: descripción breve de los sucesos ejemplares, históricos, militares y religiosos del Nuevo Mundo (1698) (Musacchio).

${ }^{4}$ Ignacio Cubas fue jefe del Archivo General. En el artículo en cuestión, el primero de Registro de enero de 1832, no aparece firma alguna.

${ }^{5}$ Se refiere al Registro trimestre o colección de memorias de historia, literatura, ciencias $y$ artes, por una sociedad de literatos. I.1 (Enero de 1832). México: Oficina del Águila, 1832. Esta publicación tenía la intención de ser trimestral, como lo indica su título. "Se repartía gratuitamente a los suscriptores del diario gubernamental Registro oficial. Continuó publicándose en 1835-1836 bajo el título Revista mexicana. Periódico científico y literario". PPM, <http://books.google.com.mx/books?id=SmRFAAAAYAAJ \&printsec=frontcover\&source=gbs_ge_summary_r\&cad=0\#v=onepage\&q\&f=false > $(13 / 09 / 12)$. 
Al llegar a la ciudad, los comisionados presentaron ante la Audiencia sus credenciales, con el consiguiente gozo de sus integrantes. Los recién llegados resolvieron notificar de la orden real a Muñoz, el jueves santo (al día siguiente). Muñoz estaba en retiro en Santo Domingo. Recibió a los oidores en su cámara, de mal modo y sin cortesías. Villanueva le entregó la real cédula: "a cada palabra se demudaba más y perdía los bríos el visitador, y al acabarse la lectura, abatido cuanto antes fue soberbio, débil y cobarde en proporción de su pasada avilantez, no murmuró una palabra, no opuso la menor resistencia, escuchando anonadado la intimación de dejar el mando y salir dentro de tres horas de la ciudad, pena de la vida y de perdimiento de los bienes" (64).

Orozco señala que dio la casualidad de que Falces no había salido aún de Veracruz, por lo que los dos ex funcionarios viajaron juntos en el mismo buque. En España Felipe II recibió primero a Falces, luego a Muñoz. "El rey lo recibió con desaire y sequedad, ni se paró a escuchar disculpa ni razón, y volviéndole la espalda le dijo con desabrimiento: 'No os envié a las Indias a destruir, sino a gobernar"'. "Al día siguiente lo hallaron muerto en su aposento, sentado en un sillón, la mano en la mejilla y con manifiestas señales en el rostro, de las violentas y encontradas pasiones que le quitaron la vida" (65). ${ }^{6}$ No deja de llamar la atención que, pese a cualquier tipo de animadversión que pudiera existir entre los nuevos mexicanos en sus versiones sobre el asunto de Muñoz, es el rey el que restablece el orden e imparte justicia. La responsabilidad de la aplicación de la mano dura recae en el funcionario, no en el soberano. Su muerte súbita —en estas versiones— parecería ser una suerte de justicia poética.

En México, la Audiencia retomó el mando, las aguas se serenaron y tomaron su cauce. El marqués del Valle fue absuelto por el Consejo de Indias, después de muchos años y se le reinstalaron los bienes confiscados en 1574 .

Orozco cierra con las siguientes conclusiones: la conjuración sí existió, pero no pudo llevarse a cabo por la falta auténtica de un líder. El marqués deseaba ser rey, pero "sin comprometerse, sin arriesgarse" (70).

\footnotetext{
${ }^{6}$ Carmen Martínez Ríos, siempre con base en Suárez de Peralta, sólo dice que la muerte de Alonso Muńoz ocurrió a los pocos meses de haber vuelto de la Nueva Espańa (llegó en agosto de 1568): el 19 de diciembre de 1568. Pero no al día siguiente de su entrevista con Felipe II.
} 
Incluso en caso de haberse lanzado al proyecto, el historiador especula que la fortaleza de España hubiera podido sofocar la revuelta de la débil Colonia.

\section{LA OBRA DE TEATRO}

Estrenada el 27 de septiembre de 1838, la obra "Muñoz, visitador de México" está escrita en verso; el resultado formal, según mi opinión, no es muy afortunado. El lenguaje aspira a imitar el usado durante la Colonia, para evocar una cierta autenticidad, un cierto color local — de la misma manera que lo haría Riva Palacio y otros novelistas que ubicaron sus textos en ese periodo. Los versos están muchas veces forzados, $\mathrm{y}$ al final se dejan varios hilos sueltos de la trama. Me interesa resaltar el tema.

En su introducción, Rodríguez Galván anota que la idea de escribir la obra de teatro le surgió a partir de la lectura de un artículo publicado en El Indicador. El texto en cuestión apareció sin firma, en dos entregas, bajo el título "Memoria. Sobre los conatos que a la independencia hubo en México desde la conquista hasta el año de 1810, y precauciones tomadas por el gobierno español para frustrarlos". ${ }^{7}$

En su introducción a la edición de la obra de teatro, Ignacio Rodríguez Galván afirma orgulloso, que tiene "casi certeza de que el primer drama histórico mexicano escrito por un mexicano, es el que ahora doy a luz; y no tengo noticia de ningún drama original mexicano que se haya publicado después de la Independencia a la fecha" (4). ${ }^{8}$ Luego da cuenta de la buena recepción que ha tenido su drama: "El espíritu nacional se despertó en las almas generosas de mis compatriotas, y a él quizá debo mi triunfo" (4). Este éxito, concluye, es el que lo ha llevado a publicar la obra. No queda duda, pues, de la intención nacionalista del dramaturgo.

A Rodríguez Galván le importó, entonces, incluir en su obra de teatro - como núcleo emocional a favor de la Independencia de la Nueva

${ }^{7}$ El Indicador de la Federación Mexicana. México. III.5 (5 de marzo de 1834): 117 143.

${ }^{8}$ Es posible que varios escritores mexicanos hayan aspirado al éxito, en cuanto a fama e ingresos, alcanzado por Alexandre Dumas. El primero de sus dramas históricos exitosos fue Henri III et sa cour, representado en 1829. 
España, concretado en el odio y el temor generalizado hacia Muñoz-, la invención de la anécdota de amor interrumpido (en dos parejas, una principal, otra secundaria). Es posible que Rodríguez Galván también tuviera en mente los problemas recientes con Francia, la llamada "guerra de los pasteles"; Francia y México habían roto relaciones diplomáticas en abril del mismo año, y existía la posibilidad de que México fuera invadido y gobernado por esta potencia europea. En cualquier caso, es sabido que la construcción de un enemigo externo siempre ha resultado de utilidad cuando se trata de concitar la unidad interna, nacional.

Esta trama parece haber sido inventada en su totalidad por Rodríguez Galván. La historia del amor interrumpido apela directamente a las emociones de los espectadores (luego los lectores) de la obra de Rodríguez Galván. A través de esa identificación con las víctimas, queda subrayado el carácter villanesco y tiranesco de Muñoz. Además, el visitador queda expuesto como un mal funcionario de la Corona, la cual, a su vez, es criticada por la pésima elección de su representante.

La obra de teatro inicia cuando el criado de Muñoz le trae informes sobre una dama que le ha interesado. Previo soborno a la criada, esa misma noche el visitador se lanza a visitarla — valga la redundancia-, pese a que ya ha sido informado de que está comprometida para casarse con Baltasar Sotelo. Se plantea ya el abuso de poder de parte de Muñoz.

El visitador intenta enamorar a doña Celestina de Albornoz. Después de declarar su amor, no olvida declarar su poder. Para apuntalar la afirmación, y de paso infundir miedo a la dama, Muñoz menciona la conspiración del marqués del Valle y el hecho de que todos los participantes son ya prisioneros. No hay mayor información al respecto, ni de las razones de las detenciones, ni de la participación del marqués. Me parece importante esta omisión, pues al dejarlo fuera, el peso de la idea de la independencia recae más en los habitantes de la Colonia, así sean españoles o criollos. De hecho, Rodríguez Galván menciona varias veces al "pueblo", sin que se sepa bien a bien a qué se refiere. Importa seńalar, pues, que esta conspiración parece desarrollarse más bien, o tomar mayor ímpetu, a partir del interés amoroso del visitador en la joven dama comprometida y lo que sucede como consecuencia de ello. El asunto amoroso opera como catalizador.

Sotelo llega a la casa. Muñoz ordena a Tristán Núñez, su criado, esconderse detrás de una cortina, y matar a Baltasar en caso de que Ce- 
lestina mencione el nombre del visitador. Sotelo ve huir a un hombre y quiere conocer su identidad. Celestina sabe que el criado matará al amado en cuanto mencione el nombre de Muñoz. Llevado por las apariencias, Sotelo cree, comprensiblemente, que ella lo engaña. Dominado por los celos, por la ira, ataca a Celestina y casi la mata. Ella le pide perdón por no poder hablar. Sotelo abandona la habitación, dejando a la dama casi muerta, en el piso.

En otra escena, varios de los conjurados, entre ellos Pedro y Baltasar de Quesada, Fernando de Bocanegra, más otros tres, quieren matar a Muñoz, pero no por odio, sino por justicia. $Y$ en esta escena es donde se plantea claramente el elemento independentista de la conspiración: "que mi mano / diera ejemplo al mexicano / de ser libre, y de ser fuerte!" (65), exclama uno de ellos. Abundan en las características negativas del visitador, y manifiestan estar dispuestos a morir por la libertad. Pedro, en particular, dice que no hay que asesinar a Muńoz, porque eso es de cobardes. Los conspiradores, pues, desean —en esta versión-, liberarse de Espańa y que la justicia se encargue de castigar al tirano Muñoz, en tanto que gobernador representante de la Corona. Así, Rodríguez Galván imbuyó a los rebeldes de un espíritu independentista, ávido de justicia, que no aparece mencionado en el artículo de El Indicador, pero que le aseguraba al novel dramaturgo una buena recepción de parte de los mexicanos recién estrenados en su nacionalidad y nacionalismo.

Sotelo, luego de abandonar a Celestina, reconoce y lamenta sus celos. Tristán Núnez, criado de Muñoz, ha entablado una relación amorosa con Bertha, una sirvienta de Celestina. Si bien hasta este momento ha obedecido al visitador, reconoce su crueldad. Tristán y Bertha informan a Sotelo de la verdad de lo sucedido: de haber mencionado Celestina el nombre de Muñoz, Tristán tenía órdenes de matar al prometido. Se refieren a Muñoz como "el déspota fiero". Bertha informa a Sotelo, además, de que Muñoz se ha llevado a Celestina a Palacio. Los criados dicen que podrán ingresar al lugar gracias a la amistad con Núnez.

Celestina, en Palacio, se lamenta de su suerte. Muñoz aparece y vuelve a hacer alarde de su poder, de su fortuna. Dice mentiras sobre Sotelo, que ella no cree. Celestina, como los conjurados, también menciona al "oprimido pueblo mexicano". Ella saca un puñal que ha escondido, y amenaza con matarse si el visitador se le acerca. Muñoz la amenaza con segar la vida de Bertha, de Sotelo. Celestina dice que de cualquier 
modo se matará. Hay que mencionar que sólo tenemos la palabra de la mujer para documentar la opresión del pueblo mexicano, pues no hemos visto pruebas de ella.

Muñoz se va y aparece Bertha, quien ha acompañado a Sotelo y a Tristán. Ella también habla del "pueblo" que se levantará en contra de la tiranía del visitador. Lleva a Sotelo con Celestina. Los amantes se reconcilian. Sotelo habla de sí mismo como el liberador de Celestina, y también del "pueblo". Dice estar cumpliendo con su destino.

Vienen guardias, avisa Tristán. Todos parten, menos Bertha, que intentará — de manera más bien ilusa- detener a los guardias; está dispuesta a sacrificar su vida. Así sucede. Muñoz mismo la mata con un puñal. Luego de la muerte de su amada Bertha, comprensiblemente, Núnez ha cambiado totalmente de bando. Es el segundo de los amores interrumpidos por las acciones del visitador. Celestina, sin embargo, le dice a Tristán que ella está en contra del sentimiento de venganza.

Baltasar llega con otros personajes, todos dispuestos a acabar con el tirano. En caso de que muera, Baltasar ha dispuesto que su hermano se ocupe de Celestina. Ella dice que tal vez sería mejor huir del país, pero él dice que es imposible no castigar al "déspota fiero" (131).

En la siguiente escena, Baltasar arenga a los conjurados y dice que si mueren, será con honor. Ahora ya hablan de venganza, más que de justicia.

Sotelo se despide emocionado de Celestina, con la convicción de que hay que libertar a México. Agrega: "el déspota mi honor ha mancillado", al haber pretendido a su prometida. Pasa de la afrenta al país, a la ofensa a su amada; de lo colectivo a lo individual, de lo público a lo privado.

Entretanto, el sufrimiento y la desesperación de Celestina se han prolongado y son sumamente intensos; hay indicios de que ha comenzado a perder la cordura. Reaparece Muñoz, quien insiste en su amor, y promete llevarla a Espańa cuando lo mande a llamar el rey. Ella le pide que la mate. Poco después llegan algunos soldados con el cadáver de Sotelo. Muñoz se lo muestra a Celestina; ella se abraza al amado y muere, aparentemente por la fuerte impresión. En un despliegue inusitado de emoción, Muñoz se muestra aterrado por la muerte de Celestina, e incluso pide a los soldados que lo maten. El visitador tiene la última palabra en el drama, exclamando, de manera sorprendente, arrepentido: “Soldados, huid de mí, que yo mismo me detesto!”. El amor, es la 
implicación, así sea un tirano el que lo experimente, es capaz de humanizar y tal vez de redimir.

El efecto teatral parece ser lo que más le interesa a este novel dramaturgo. Si bien introduce el sentir independentista, éste se vincula con la oposición a la figura del cruel visitador, y al inventado pretexto amoroso. Es decir, la "argumentación" a favor de la independencia se da sobre todo en el campo emocional, no en el ideológico. Se dejan sueltos hilos muy importantes: las causas de la conspiración, el lugar que ocupó en ésta el marqués del Valle, el éxito o fracaso de la revuelta en contra de Muñoz después de la muerte de Celestina, y el de la suerte del visitador. Se castiga al visitador al menos de una manera inmediata, en sus sentimientos, con la muerte de Celestina, pero sigue vivo y en la Nueva España. A Rodríguez parecería bastarle con el intento de revuelta en contra del tirano, con los discursos a favor de la independencia, con los calificativos de déspota, acompañados de diversos adjetivos.

\section{Dos CAPítulos en EL LIBRO ROJO}

Carlos Montemayor, en su prólogo a El libro rojo en la edición de Conaculta, identifica la conspiración como el primer esbozo de un movimiento independentista - aunque tal vez sea con cierto optimismo, pues, a juzgar por el recuento de Orozco, si bien no en el de Rodríguez Galván ni en el de Payno queda la impresión de que el marqués simplemente deseaba tomar el poder, por el poder y lo que conlleva, sin mayores consideraciones de libertad o independencia de los súbditos novohispanos. De hecho, los diversos acontecimientos que llevan a las detenciones —en la versión de Orozco- apuntan en esa dirección. Con esa sospecha, es posible que a estos autores que toman el tema, se les haga más fácil centrarse en el autoritarismo, la crueldad y arbitrariedad del visitador — sobre todo en la medida en que se trataba de un alto funcionario español.

Manuel Payno también se ocupó del visitador Muñoz en El libro rojo, publicado originalmente en 1870. Son dos los capítulos que nos incumben: "Alonso de Ávila" y "Don Martín Cortés"; para ellos Payno menciona que se basó en la ya mencionada Noticia histórica de la conjuración del marqués del Valle. Años 1565-1568 (1853) de Manuel Orozco y Berra y en el libro de Torquemada, Monarquia indiana. Hay 
una nota a pie del propio Payno, donde escribe: "Los datos están tomados de Torquemada, el padre Cabo [sic], ${ }^{9}$ y especialmente de la curiosa noticia histórica escrita por don Manuel Orozco y Berra. Algunos de los pormenores se encuentran esparcidos en las crónicas de los conventos; así en estos estudios no hacemos sino animar a los personajes y ponerlos por un instante de bulto ante el lector, pero conservando en todo la verdad histórica" (n. 1, 98). Si bien Payno se cuida de afirmar que ha conservado "la verdad histórica", en la escritura de sus capítulos no duda en aventurar diálogos y descripciones con fines de eficacia narrativa.

Como epígrafe, Payno coloca una cita de la obra teatral de Rodríguez Galván, en una intertextualidad literaria e histórica: "Mandaré decapitar / a todos los sospechosos, / con suplicios espantosos / haré a México temblar". La intención de sentido es clara: se resalta la crueldad del de la voz (Muñoz) y el agravio infringido al recipiendario de su crueldad: México.

Payno, lo sabemos, es un excelente narrador. Si bien se basa en los libros ya mencionados, adereza la historia, llena imaginativamente los huecos de sus fuentes, y sobre todo, vincula los sitios mencionados en el recuento, con los geográficos de la ciudad en su presente del siglo XIX, estableciendo así un ir y venir del pasado colonial a su presente decimonónico.

El capítulo "Alonso de Ávila" comienza de manera muy dramática y eficiente, "en medio de una noche oscura y lluviosa", cuando el virrey Luis de Velasco agoniza, y mientras un criado busca entre los dominicos atención espiritual para su patrón, don Fortún del Portillo, en un trance similar al del virrey. Don Fortún dice al sacerdote su confesión en secreto (para el lector), quien se alarma ante la información recibida. El fraile apenas alcanza a absolver al moribundo, pues es evidente que tiene prisa por dar a conocer a alguien lo escuchado. Este arranque es sumamente eficaz, pues ya ha picado la curiosidad del lector. El fraile dice que tiene que acudir al visitador Valderrama. En pleno suspenso, Payno cierra este primer apartado.

En el siguiente se ocupa de la segunda generación de los conquistadores en la Nueva España, entre los cuales la figura de Martín Cortés era especialmente brillante. Sus numerosas posesiones, su figura, su esposa, "le dieron tal prestigio, que México le vio, si no como el verda-

\footnotetext{
${ }^{9}$ Véase la nota 8.
} 
dero monarca de este reino, al menos como su más fiel y respetable imagen" (98).

La narración de Payno es vívida y minuciosa, con detalladas descripciones y diálogos ágiles. Estamos - y la primera persona del plural es adecuada, porque Payno logra que el lector sea un testigo cercano en las escenas- en vísperas de la celebración del bautismo de los gemelos hijos del marqués, quien desea que sean "fiestas verdaderamente reales" (100). Alonso de Ávila y el marqués comentan el estado de la conspiración, los informes que puede tener de ella tanto Valderrama como la Audiencia. En este punto es cuando Payno introduce, en boca del marqués, el elemento de la libertad: "en medio de las festividades" organizaremos "que la tierra quede por nuestra, y libre de la tiranía de España y del despotismo de los oidores y visitadores. Lo que el padre quiso dar al rey, el hijo no lo quiere confirmar" (100-101).

Dada la información contenida en Orozco, no deja de asombrar esta afirmación, pues refiere que los oidores, en ese momento, no ejercían su autoridad y más podrían ser acusados de negligencia. Mostrarán una cara más dura cuando se adelantan al estallido de la toma de poder de parte del marqués, pero todavía no llega ese momento. En cuanto al "despotismo" de los visitadores, el propio marqués acaba de informar que Valderrama es su huésped y amigo, y que ha logrado convencerlo de que no hay conspiración alguna.

Hace luego Payno una pausa para informar sobre los edificios del centro de la ciudad, y su estado en tiempos del marqués, siempre en comparación y contraste con su presente del siglo XIX. La pausa sirve para incrementar el suspenso, además de dar datos útiles e interesantes para su lector contemporáneo.

El siguiente capítulo describe en detalle las celebraciones del bautismo. Se llevó a cabo entonces una suerte de representación, en la cual varios de los participantes llegaron disfrazados de indios. Colocaron éstos coronas de laurel en la cabeza de los marqueses, al tiempo que exclamaban: “¡Oh! ¡Qué bien les están las coronas a vuestras señorías!" (101). Después de ello, Ávila conversa con otro tertuliano, y ambos brindan "por el légitimo y futuro soberano de México" (102). El mismo don Alonso agrega que los encomenderos los apoyan, ante el peligro de perder la concesión de sus propiedades, y añade una afirmación que resulta un poco sorpresiva: "los indígenas veneran la memoria del conquistador y aman al marqués” (107). Y remata: “ipor qué hemos de 
sufrir por más tiempo el yugo y la dependencia de España? Hagámonos señores de la tierra que nuestros padres conquistaron con su sangre, dictemos leyes para nuestra felicidad, sacudamos la tiranía y arrojemos a todos esos virreyes, oidores y visitadores que vienen a poner el pie en nuestros cuellos. ¡Viva la independencia, viva el marqués del Valle, nuestro seńor!" (107).

Ávila, quien aparece como líder, informa a los asistentes de los detalles del levantamiento, que necesariamente incluye derramamiento de sangre. La perspectiva de la violencia congela la sonrisa de algunos. Conocedor del desenlace de la conspiración, el narrador incluye algunas premoniciones funestas en la percepción del marqués, que están a tono con el romanticismo de la época: "De en medio de este torbellino de borrachos alegres y de atrevidos conspiradores, se deslizaban de vez en cuando unas figuras negras y misteriosas que desaparecían apenas alguno fijaba en ellas sus ojos. El marqués observó algo de esto una ocasión y sintió, sin saber por qué, un ligero calosfrío" (109). El fraseo es ambiguo, y, si bien sugiere la posible presencia de espías o futuros traidores, tampoco elimina algún elemento sobrenatural.

Pasamos luego a los oidores, ya enterados de la conspiración. Su posición es endeble, pues no poseen ni hombres ni armas comparables con las del marqués; los indios — se vuelve a mencionar- están del lado de los rebeldes. Uno de ellos sugiere la solución radical con respecto a los oidores: "No hay más remedio que ahorcarlos a todos" (110). Acuerdan, entonces, adelantarse a la rebelión y usar el elemento de la sorpresa, apresando a todos los conjurados de manera simultánea.

Se manda llamar al marqués, y — a diferencia de la versión de Orozco- se le atiende con mucha cortesía, luego de lo cual le dicen: "Daos preso por el rey" (111). Don Martín intenta defenderse, niega la acusación de traidor al rey, aparentemente ofendido. Sin embargo, envaina de nuevo la espada y acepta la detención.

El siguiente capítulo es breve y contundente: don Alonso, junto con su hermano Gil González, son ejecutados en la plaza mayor, el 3 de agosto de 1566. Antes de morir, ya en el cadalso, "Alonso confesó allí ser cierta la conspiración, con palabras que revelaban la proximidad de la muerte, y las últimas oraciones no terminaban cuando el verdugo levantó en el aire su terrible hacha, la que zumbando trozó la cabeza del apuesto y gallardo joven, y lo mismo pasó con el inocente Gil González, quedando aquel paño fúnebre humedecido con la sangre de los dos 
alegres y bravos convidados del marqués del Valle" (112). Los adjetivos del narrador dan cuenta de su posición con respecto a la conjuración.

El siguiente capítulo de El libro rojo se refiere a "Don Martín Cortés". Se inicia con la llegada de la nave que transporta al marqués de Falces, recién nombrado virrey de la Nueva España. En esta versión, algunas personas cercanas a los Ávila y al marqués del Valle lo abordan para referirle su versión del perturbador estado de cosas. El marqués de Falces, previsiblemente, desea tomar las cosas con calma y tarda un mes en llegar a la ciudad de México.

"Don Gastón de Peralta, marqués de Falces, tercer virrey de México, era hombre generoso, franco, enemigo de las violencias y de las persecuciones, y sobre todo respetaba la memoria del conquistador y estaba dispuesto a perdonar cualquier falta que sus descendientes hubiesen cometido" (117), escribe Payno.

Ya en la ciudad, la manera de ocuparse de la conspiración, de parte de la audiencia y de Falces, no podía ser más distinta. Los oidores tenían guardias por doquier y había un estado de temor e inquietud generalizado. Falces, por su parte, negó la confiscación de los bienes de Cortés. La audiencia amenazaba con degollarlo. Falces lleva entonces a cabo una entrevista con el marqués del Valle, en la que quedan claras sus intenciones de protegerlo y desactivar el ímpetu de la Audiencia. Esta actitud, está consciente, puede costarle el virreino, pero dice: "Quiero salvar el nombre histórico de los españoles. Tres viejos miserables, llenos de odio y de rencor, no deben enviar al patíbulo a los hijos del capitán más grande que ha tenido Europa" (118). Le informa que será enviado a España, a ser juzgado por el rey, en tanto que su hermano Luis, si bien sentenciado a muerte, sólo será desterrado a Orán por diez años. Luego manda llamar Falces a los oidores, para comunicarles sus decisiones. Al día siguiente, los presos pendientes fueron liberados.

Como es comprensible, la Audiencia no quedó contenta, por lo que procedió a acusar al virrey de complicidad con el marqués del Valle, además de otras "calumnias".

Finalmente, en la sección que lleva su nombre, aparece ya "El visitador Muñoz". Felipe II envió a tres visitadores a la Nueva España. Jarava, Carrillo y Muñoz, escribe el narrador, "eran tres fieras y no tres hombres" (120). Vale la pena transcribir el párrafo dedicado a la descripción de Muñoz: "el licenciado Alonso de Muñoz era hombre de más de 65 años: alto, seco, acartonado, de color de aceituna, de ojos 
torvos y hundidos, de una boca tosca y antipática; sus facciones todas salientes y duras, sus barbas gruesas como las cerdas de un jabalí, y que le salían en desorden por toda la cara hasta cerca de los ojos, lo hacían parecer más bien un animal feroz que un ser humano; todo, en fin, revelaba su altanería, su crueldad y su orgullo" (121). Con una pinta tal, este personaje no puede sino ser un terrible tirano.

Al decir de Payno, el primer encuentro entre Muñoz y la Audiencia no es precisamente amable ni cordial. De inmediato solicitó ver las actas de los procesos. Se ordenó luego la confiscación de los bienes de los hermanos Cortés, y la aprehensión de quienes ya habían sido liberados, que sumaban doscientos. Volvió el terror a reinar en la sociedad novohispana. Hubo más decapitados; otros enviados a Espańa. Además, se impusieron fuertes multas que, según Payno, "se repartían Muñoz, Carrillo, los oidores y los demás satélites del tirano” (124). A la crueldad se aúna la corrupción.

Estas acciones sólo provocaron el nacimiento de una conspiración nueva, esta vez para deshacerse de Muñoz y de la Audiencia. Las quejas, ahora sobre la conducta de Muñoz, llegaron a la Corte. El rey envió a dos comisionados (Puga y Villanueva) a resolver los problemas ocasionados por el visitador.

Durante la semana santa el temible visitador hizo un retiro espiritual en el convento de Santo Domingo. Lejos de dedicar su tiempo a la oración, dice el narrador, "se encerraba en su celda a pensar a quiénes robaría los bienes y a quién encerraría en sus inmundos calabozos" (127).

Puga y Villanueva acudieron el miércoles santo a entregar las nuevas órdenes a Muñoz. Le dieron tres horas para abandonar la ciudad. El visitador nada reparó y salió en cuanto le fue posible, con destino a Veracruz. Cuando se difundió la noticia de su partida, escribe el narrador, "la ciudad se llenó de júbilo, y las gentes salían de sus casas como si se hubieran repetido las espléndidas fiestas del marqués" (128).

En el barco hacia España coincidieron Falces y Muñoz. Según esta versión, Muñoz intentó hablar con el marqués, sólo para recibir la siguiente respuesta: "Un caballero y un hidalgo no puede atravesar una palabra [...] con un asesino y un hombre vil" (129).

En la corte, Falces fue bien recibido. Muñoz, en cambio, recibió la siguiente reprimenda de Felipe II: "No os envié a las Indias a destruir, sino a gobernar" (129). Los criados lo encontraron al día siguiente, muerto en una silla, "con una mano en la mejilla y la fisonomía des- 
compuesta y hundida". Y concluye: "Así se cumplió la justicia de dios y del rey" (129).

Payno toma los hechos básicos, pero se toma las libertades propias de un literato, para aderezar las situaciones y los personajes, llenando los huecos de la narración histórica con escenas, pensamientos, reflexiones, conductas, diálogos atribuibles a los actores, que pudieron haber pasado como él propone. No tuvo que recurrir al tema del amor interrumpido, como antes de él lo hizo Rodríguez Galván, y luego hará el autor anónimo del siguiente texto.

\section{Un CUENTO ANÓNIMO}

El tercer texto ("El visitador") que se ocupa del mismo personaje, es un cuento anónimo, publicado en 1900 en dos entregas en El Tiempo, el periódico conservador de Victoriano Agüeros, y luego en el libro de la misma casa editorial, que reunió varias narraciones.

Si bien el autor anónimo de este cuento no aprovecha la conspiración de Martín Cortés como un elemento histórico temprano a favor de la independencia, sí hay que mencionar que existen señales que apuntan hacia el nacionalismo del narrador. En el primer párrafo, cuando se establece la ubicación y el tiempo se la define como "la ciudad conquistada". Luego de mencionar la atmósfera de temor debido a la incertidumbre en torno a la conspiración atribuida al marqués del Valle, pero sobre todo a la actuación del visitador Muñoz, el narrador escribe que parecía haber caído una maldición "sobre la patria de Moctezuma". Se distancia, así, de los conquistadores, en particular del cruel Muñoz, y se acerca conscientemente al pasado prehispánico.

El narrador del cuento tiene algunas intenciones didácticas en el campo de la historia, pues describe y anota detalles de la época de la Colonia, indicando causas y costumbres. En esta medida, es claro, es tanto costumbrista como romántico e histórico. Por ejemplo, cuando describe la vestimenta del visitador, indica que la capa negra y la golilla era como se vestían, "hasta principios de este siglo [es decir, el suyo, el xIx] los abogados". De igual manera, al ocuparse de los Cervantes, anota el narrador que éste era un encomendero, para luego explicar qué eran las encomiendas. Tiene cuidado de mencionar que a principios de la Colonia se trataba a los indios como esclavos, y que luego 
fue necesario indicar en concilios y decretos, que los "indios nacían libres".

Es interesante que en el cuento no se aclara nunca si Baltasar de Quesada (los nombres cambian) participó o no de la conspiración. Ana, al menos, siempre está convencida de la inocencia de su prometido. El énfasis cae en la trama amorosa y el amor interrumpido por capricho de Muñoz. Es decir, el ataque del narrador se centra en el visitador y su tiránica administración.

Cuando el visitador acaba de ver a Ana y ya ha recabado información sobre su persona, pasa la noche inquieto, pensando en ella, aunque "frecuentemente fijando su pensamiento en las ideas de conspiración y traidores de que estaba habitualmente lleno" - lo cual sugiere que no había tal o que su imaginación magnificaba lo poco que hubiera en ese sentido.

Quesada es aprehendido al salir de casa de Ana. El narrador comenta que la sospecha del visitador bastaba para encarcelar a una persona, y que no había diferencia entre ser preso y ser condenado. (En este sentido, el personaje podría jugar un papel similar al de la Inquisición en narraciones posteriores como las de Riva Palacio, donde parte de lo que se deseaba plantear era la arbitrariedad y abuso del poder de parte de las instituciones españolas - en este caso, gubernamentales, en el otro, religiosas, aunque íntimamente vinculadas con el gobierno. En ambos casos, el paralelo está implícito: ahora que somos independientes, ya no estamos sujetos sino a nuestros gobiernos e instituciones.) El propio Muñoz fungía como juez, revisando escrupulosamente las declaraciones, para aferrarse a cualquier incongruencia o contradicción, que le bastaba para dictar sentencia. Y agrega el narrador que el visitador, como "otros magistrados de siglos posteriores", no estaba dispuesto a dar marcha atrás ni a aceptar algún error, sin importar el funesto resultado para el preso.

Muñoz logra ingresar a casa de Ana mediante la distribución de algunas monedas entre la servidumbre (el cuento sigue de cerca la obra de teatro). Le declara su amor de inmediato, antes de dar a conocer su identidad. Ella se rehúsa, pues se considera esposa de Quesada. Cuando el visitador expone quién es, abre las cartas del poder, que intenta ejercer directamente sobre la dama, como ya lo ejerció físicamente sobre el esposo. Ana debe actuar sensata y prudentemente, pues si bien ha concertado previamente la libertad de Baltasar (mediante otro soborno), 
sabe también que no debe provocar la ira de Muñoz. El visitador insiste en que ella debe renunciar al amor por Baltasar, y sentencia, proféticamente: "Ese amor le perjudica, ese amor es su verdugo, es el puñal que va a atravesarle el corazón".

Sin ver otra salida para librarse del visitador, Ana promete no volver a ver a su esposo, justo en el momento en que éste, recién liberado, llega a la habitación sin ser percibido. Advierte el coloquio, que malinterpreta. Sin mayores explicaciones ni preámbulos, asesina a la amada. Cumple, así, la recién expresada profecía del visitador. (Aquí se separa un poco el cuento de la obra de teatro: en la segunda, el prometido está a punto de matar a la amada, pero no lo hace.) Como suele suceder, una serie de coincidencias trágicas se confabulan para que todo salga mal. Los malentendidos, los celos de Baltasar, la pasión de Muñoz, ocasionan desenlaces trágicos. Ana pasa exactamente por el proceso inverso que mal imagina su esposo, pues ha prometido no volver a verlo para no provocar la ira del visitador y salvarlos a ambos.

Muñoz ordena de nuevo la aprehensión de Quesada, aunque ahora sí ha cometido un delito, un homicidio. Días después, lo lleva a que se confiese a un monasterio. Durante ese proceso, el acusado se arrepiente y atribuye el malentendido a la enemistad del visitador. El confesor, un hombre sensato, conciliador y justo, lo comenta con el funcionario, intentando suavizar la sentencia. Sus palabras no tienen eco alguno, como era previsible, y al día siguiente se ejecuta al asesino. Al menos ha salvado su alma. Como mencioné antes, en este cuento la conjura es casi inexistente.

El cuento termina un tanto abruptamente, pues sin mayores explicaciones, sin causas aparentes, luego de la ejecución de los "traidores", de pronto Muñoz ya está de vuelta en España, donde se narra la anécdota también incluida por Orozco, en El Indicador y en Payno. Es curioso que el autor anónimo diga que son traidores, pues no ha incluido señal alguna en el cuento en ese sentido. Simplemente hay que creerle. Especulo: tal vez confiaba - temerariamente- en que sus lectores estaban al tanto de los pormenores de la conspiración, del desarrollo y el desenlace.

Felipe II reclama a Muñoz su proceder con la frase: "Os envié a las Indias a gobernar, no a destruir". Se repite, igualmente, el funesto desenlace, relatado tanto por Orozco y Berra como por Payno. Aunque los amantes han quedado separados y ambos murieron, al menos hay 
un mínimo consuelo para el lector, pues el desprecio y censura del rey al villano del cuento, ocasiona su muerte. No se trata estrictamente de impartición de justicia humana, pero el temible visitador es castigado con la humillación de parte del soberano y, también, suponemos, en el otro mundo. Si la intención del autor hubiera sido más política, la conspiración de Martín Cortés, el desempeño del visitador, así como la salida de Muñoz de la Nueva España hubieran dado pie a una trama tal vez distinta.

El narrador anónimo tiene cuidado de añadir que quienes caían bajo la sospecha del visitador fueron condenados al exilio, la cárcel o el cadalso, es decir, no se impartió de manera adecuada, con criterio, ni la ley ni la justicia; no se siguió el debido proceso, diríamos ahora. Se trata de otra instancia más de arbitrariedad planteada por los narradores mexicanos del siglo XIx, en su afán de establecer una distancia tajante de Espańa y proporcionar más razones —así sean a posteriori y sobre todo emocionales - para la Independencia. El abuso es perpetrado por los funcionarios nombrados por el rey, de quien por cierto, el narrador dice estaba "sediento de sangre" y molesto ante la posibilidad de perder parte de sus colonias - como parecía indicar la conspiración del marqués del Valle. Al final del cuento, sin embargo, Felipe II es reivindicado de alguna manera, pues incluso este rey, que al principio parece dispuesto a todo con tal de sofocar cualquier brote independentista, censura acremente la conducta opresora, represora y cruel del visitador.

\section{A MANERA DE CONCLUSIÓN}

En resumen: tanto Payno como el autor anónimo establecen un contraste entre la crueldad de Muñoz y la bonhomía del virrey, el marqués de Falces. Ambos mencionan de pasada la revuelta de Martín Cortés, marqués del Valle, en parte para establecer la atmósfera de inquietud y conspiraciones que privaba en la Colonia. Luego de mencionar estos nombres al inicio del cuento, que no vuelven a aparecer más, la trama se centra en la anécdota que ilustra la arbitrariedad del visitador. La versión de Suárez de Peralta, como mencionamos, no es tan enfática con respecto a esta crueldad, y de hecho alude más bien a la de Carrillo.

En los tres casos literarios (la obra de teatro, los capítulos, el cuento), el centro de atención es el cruel y arbitrario proceder de parte de un 
funcionario español, interpretando la ley a fin de aplicarla del modo más duro posible. El funcionario, es claro, representa la peor actitud de la Corona hacia la Nueva España.

No sorprende que, en dos de las tres instancias estemos frente a un caso de amor interrumpido. Estos dos textos se ocupan más de la intriga amorosa, en lugar de desarrollar la parte política. Es posible que los dos autores hayan tenido en cuenta a los posibles lectores —en realidad tal vez más a las lectoras-, que podrían interesarse más en lo primero que en lo segundo.

En la obra de teatro y en el cuento estamos frente a una historia de abuso de poder, de los caprichos de un gobernante, de la pasión que ciega a un amante, del sacrificio de una mujer con tal de conseguir la libertad del amado, de malentendidos, de dejarse llevar por la primera impresión, por la pasión momentánea.

Rodríguez Galván sí imbuye a la historia de una dosis nacionalista evidente, de rebelión en contra del tirano, aunque la anécdota central sea la amorosa. Sin embargo, creo que la dosis nacionalista está metida un poco a la fuerza. Mientras que el autor del cuento sigue a Rodríguez Galván en la trama amorosa, no coinciden en el plano político.

\section{BiBLIOGRAFÍA}

Anónimo. "Memoria. Sobre los conatos que a la independencia hubo en México desde la conquista hasta el año de 1810, y precauciones tomadas por el gobierno español para frustrarlos". El Indicador de la Federación Mexicana. México. III.5 (5 de marzo de 1834): 117-143. [Manuel Orozco y Berra le atribuye la autoría a Ignacio Cubas.]

Anónimo. "El visitador". En dos entregas en El Tiempo. Diario Católico. a) Año XVIII, núm. 5152. México: Imprenta de Victoriano Agüeros, 27 de noviembre de 1900: 1, 4. b) Año XVIII, núm. 5152, 27 de noviembre de 1900: 1 y 4. También en Novelas cortas de varios autores. Biblioteca de Autores Mexicanos 37. México: Imp. de Victoriano Agüeros, 1901. II: 413-433.

De Groot, Jerôme. The Historical Novel. Col. The New Critical Idiom. Nueva York: Routledge, 2010.

FernÁNDEZ DE Montesinos, José F. Introducción a una historia de la novela en España en el siglo XIX. Madrid: Castalia, 1982.

Fuentes, Carlos. El naranjo o los círculos del tiempo. México: Alfaguara, 1993. 
Gil Amate, Virginia. "Crónicas del siglo xvi, cuentos del siglo xx”. Biblioteca virtual Miguel Cervantes. <http://www.cervantesvirtual.com/obra/ crnicas-del-siglo-xvi-cuentos-del-siglo-xx---juan-surez-de-peralta-a-travs-de-carlos-fuentes-0/> (7/02/2014).

Illades, Carlos. Nación, sociedad y utopía en el romanticismo mexicano. México: Conaculta, 2005.

Jiménez Rueda, Julio. "Prólogo". Muñoz, visitador de México [1947]. Biblioteca del Estudiante Universitario, 67. 2a ed. México: Universidad Nacional Autónoma de México, 1995: v-xviii.

J.M.L. "Netzula". El Año Nuevo. 1832. El Año Nuevo de 1837. México: Librería de Galván, 1837: 15-52. También publicado en Celia Miranda, La novela corta en el primer romanticismo mexicano. México: Universidad Nacional Autónoma de México, 1985: 129-151.

Lukács, Georg. The Historical Novel. Trad. del alemán de Hannah y Tanley Mitchell. Lincoln: University of Nebraska Press, 1983. $1^{\text {a }}$ reimpresión.

Maigron, André. Roman historique à l'époque romantique [1912]. Memphis, TN: General Books LLCtm, 2012.

Martínez Ríos, Carmen. "Alonso Muñoz, consejero de Indias". Historia y patrimonio. 6-49, <http://servicios.laverdad.es/fiestas/caravaca02/revista/pdf/tomo1/Alonso\%20Mu\%F1oz.pdf> (7/02/2014).

Miranda Cárabes, Celia. La novela corta en el primer romanticismo mexicano. Ed. Celia Miranda Cárabes. México: Universidad Nacional Autónoma de México, 1985.

Montemayor, Carlos. "Prólogo”. El libro rojo. Col. Cien de México. México: Conaculta, 2006. 2a reimpr.: 9-18.

Musacchio, Humberto. Diccionario Enciclopédico de México. 4 vols. México: Andrés León, ed., 1989.

Orozco y Berra, Manuel. Noticia histórica de la conjuración del marqués del Valle. Años 1565-1568. México: Edición del Universal, 1853.

Ortega, Eulalio. "La batalla de Otumba". El Año Nuevo. Presente Amistoso. México: Librería de Galván, Portal de Agustinos número 3, 1837: 180188.

Pacheco, José Emilio. "A 150 años de la Academia de Letrán. Discurso de ingreso al Colegio Nacional el 10 de julio de 1986". <www.colegionacional.org.mx/SACSCM5/xStatic/colegionacional/docs/espanol/05_jose_emilio_p>.

Perales Ojeda, Alicia. Las asociaciones literarias mexicanas. México: Universidad Nacional Autónoma de México, 2005.

Publicaciones periódicas mexicanas del siglo XIX: 1822-1855. Coords. Miguel Ángel Castro y Guadalupe Curiel. México: Universidad Nacional Autónoma de México, 2000. 
Payno, Manuel y Vicente Riva Palacio. El libro rojo. Col. Cien de México. México: Conaculta, 2006. 2a reimpr.

Prieto, Guillermo. Memorias de mis tiempos. Obras completas I. $1^{\mathrm{a}}$ reimpresión. México: Conaculta, 2005.

Rodríguez Galván, Ignacio. Muñoz, visitador de México [1947]. Biblioteca del Estudiante Universitario, 67. 2a ed. Pról. Julio Jiménez Rueda. Universidad Nacional Autónoma de México, 1995.

Sierra O’Reilly, Justo. La hija del judío. 2 vols. Ed. Manuel Sol. Clásicos Mexicanos, 9, 10. Xalapa: Universidad Veracruzana, 2008.

Suárez de Peralta, Juan. Tratado del descubrimiento de las Yndias y su conquista. Ed. Giorgio Perissinotto. Madrid: Alianza Editorial, 1990.

Torquemada, fray Juan De. Monarquia indiana. Pról. Miguel León-Portilla. México: Porrúa, 1986, <http://www.historicas.unam.mx/publicaciones/publicadigital/monarquia/volumen/02/mi_vol02.html\#Libro05> (29/10/2012). 